\title{
Electrophoretic molecular karyotype of the dermatophyte Trichophyton rubrum
}

\author{
Eliane P. Cervelatti, Monica S. Ferreira-Nozawa, Roseli Aquino-Ferreira, Ana Lúcia Fachin \\ and Nilce M. Martinez-Rossi \\ Universidade de São Paulo, Faculdade de Medicina de Ribeirão Preto, Departamento de Genética, \\ Ribeirão Preto, SP, Brazil.
}

\begin{abstract}
The electrophoretic karyotype of the dermatophyte Trichophyton rubrum was established using contour-clamped homogeneous electric field (CHEF) gel electrophoresis. Five chromosomal bands of approximately 3.0 to 5.8 megabase pairs (Mbp) each were observed and together indicated that $22.05 \mathrm{Mbp}$ of the total genome are organized as chromosomal macromolecules. In addition to establishing the number and size of $T$. rubrum chromosomes, these results open perspectives for the construction of chromosome-specific libraries and for the physical mapping of genes of interest, thus permitting future gene linkage studies in this pathogen. A detailed understanding of the karyotype and genomic organization of $T$. rubrum should contribute to further genetic, taxonomic and epidemiological studies of this dermatophyte.
\end{abstract}

Key words: Trichophyton rubrum, fungal chromosomes, electrophoretic karyotype, dermatophyte, contour-clamped homogeneous electric field.

Received: March 18, 2003; Accepted: September 2, 2003.

\section{Introduction}

Trichophyton rubrum is a cosmopolitan filamentous fungus that can infect human keratinized tissue (skin, nails and, rarely, hair), and is one of the most frequently encountered dermatophytes (Costa et al., 2002; Jennings et al., 2002; Monod et al., 2002). This pathogen, which normally causes well-characterized superficial infections, also produces skin infections in unusual parts of the body in immunodepressed patients (Squeo et al., 1998; Sentamilselvi et al., 1998; Smith et al., 2001). Despite the incidence and medical importance of this dermatophyte, little is known about its genetic and biological characteristics. Classic genetic analysis is not possible with T. rubrum because no sexual phase is known. In addition, the number of chromosomes in this species has not been determined by light microscopy since mitotic material is generally unsuitable for the study of fungal chromosomes (Zolan, 1995).

Pulse-field gel electrophoresis (PFGE) is an effective method for separating chromosome-sized DNA, and is an important tool for basic genetic studies, especially in lower eukaryotes such as fungi and yeasts. Furthermore, summa-

Send correspondence to Nilce M. Martinez-Rossi. Universidade de São Paulo, Faculdade de Medicina de Ribeirão Preto, Departamento de Genética, Ribeirão Preto, SP, Brazil. E-mail: nmmrossi@ fmrp.usp.br. tion of the sizes of the different molecules separated by this technique provides an estimate of the genome size. Pulse-field gel electrophoresis and a refinement known as contour-clamped homogeneous electric field (CHEF) gel electrophoresis, has been used to determine the molecular karyotype of many fungi, including Aspergillus nidulans (Brody and Carbon, 1989), Aspergillus niger (Verdoes et al., 1994), Neurospora crassa (Orbach et al., 1988), Paracoccidioides brasiliense (Montoya et al., 1999), Aspergillus fumigatus (Tobin et al., 1997), and pathogenic yeasts such as Candida albicans and Candida glabrata (Fodor et al., 2002).

Since the karyotype of T. rubrum is unknown we have standardized the conditions for obtaining protoplasts in order to determine the electrophoretic karyotype of this species using CHEF gel electrophoresis and to estimate its genome size.

\section{Material and Methods}

Strain

A clinical isolate of T. rubrum (H6) obtained from a patient admitted to the University Hospital of Ribeirão Preto, SP, Brazil, and identified by standard methods (McGinnis, 1980; Fachin et al., 1996) was used in this study. 


\section{Preparation of intact chromosomal DNA}

After incubation of isolate H6 in Sabouraud glucose agar for 20 days at $28{ }^{\circ} \mathrm{C}$, conidia and mycelium from one petri dish were carefully harvested and incubated with $100 \mathrm{~mL}$ of liquid Sabouraud glucose medium at $28^{\circ} \mathrm{C}$ and $250 \mathrm{rpm}$ for $18 \mathrm{~h}$. The resulting mycelium was harvested by vacuum filtration through Whatman paper (Whatman International, Maidstone, UK) and washed with sterile water. Protoplasts were obtained by incubating the mycelium in $30 \mathrm{~mL}$ of lytic solution (600 mg of Glucanex (Novo Nordisk, Swiss), $50 \mathrm{mM} \mathrm{KH}_{2} \mathrm{PO}_{4}, \mathrm{pH} 7.5$, and $0.7 \mathrm{M} \mathrm{KCl}$ ) for $3-4 \mathrm{~h}$ at $28{ }^{\circ} \mathrm{C}$. The suspension of protoplasts was filtered through glass wool and the protoplasts were collected by centrifugation ( $1575 \mathrm{~g}, 5 \mathrm{~min}$ ). The pellet was resuspended and washed twice in STC buffer $(1.2 \mathrm{M}$ sorbitol, 10 $\mathrm{mM}$ Tris- $\mathrm{HCl}, \mathrm{pH} 7.5,10 \mathrm{mM} \mathrm{CaCl}_{2}$ ). The final pellet was resuspended in protoplasting buffer $(0.9 \mathrm{M}$ sorbitol, 0.125 M EDTA, $\mathrm{pH}$ 7.5) to a protoplast concentration of $1.0 \mathrm{x}$ $10^{8}-1.5 \times 10^{8}$ cells per $\mathrm{mL}$. The suspension was heated to 42 ${ }^{\circ} \mathrm{C}$ and an equal volume of molten $1.4 \%(\mathrm{w} / \mathrm{v})$ InCert agarose (Seaken Gold agarose, FMC Bioproducts) in protoplasting buffer precooled to $42{ }^{\circ} \mathrm{C}$ was added. The agarose/protoplast mixture was then poured into a plug mold and solidified at room temperature for $30 \mathrm{~min}$. Protoplast lysis was induced by adding proteinase $\mathrm{K}(2 \mathrm{mg} / \mathrm{mL})$ in digestion buffer (0.5 M EDTA, pH 8.0, $10 \mathrm{mM}$ Tris-HCl, $1 \% \mathrm{Na}-\mathrm{N}$-laurylsarcosinate) at $50{ }^{\circ} \mathrm{C}$ for $72 \mathrm{~h}$. Finally, the plug was washed three times in $50 \mathrm{mM}$ EDTA, $\mathrm{pH} 8.0$, at $50{ }^{\circ} \mathrm{C}$ and once at room temperature, and then stored at $4{ }^{\circ} \mathrm{C}$ in $50 \mathrm{mM}$ EDTA.

\section{CHEF gel electrophoresis conditions}

Agarose plugs were sealed in the wells of $0.7 \%(\mathrm{w} / \mathrm{v})$ agarose gels (Seaken Gold agarose, FMC Bioproducts). Plugs containing Schizosaccharomyces pombe and Hansenula wingei chromosomal preparations (BIO-RAD) were used as size standards. The chromosomes were separated by CHEF gel electrophoresis (CHEF-DR III BIORAD) under the following electrophoretic conditions: $72 \mathrm{~h}$, $1.5 \mathrm{Vcm}^{-1}, 60 \mathrm{~min}$ pulse, $\pm 120^{\circ}$ field angle; $144 \mathrm{~h}$, $1.4 \mathrm{Vcm}^{-1}, 45 \mathrm{~min}$ pulse, $\pm 120^{\circ}$ field angle; $76 \mathrm{~h}, 1.8 \mathrm{Vcm}^{-1}$, 25 min pulse, $\pm 120^{\circ}$ field angle; $0.5 \mathrm{X}$ TBE $(0.045 \mathrm{M}$ Tris-borate, $0.001 \mathrm{M}$ EDTA pH 8.0) at $12{ }^{\circ} \mathrm{C}$ (Tobin et al., 1997). The gels were stained with ethidium bromide and photoimaged using Kodak Digital Science ID image analysis software. To achieve a better separation of small chromosomes, the agarose plugs were sealed in the wells of a $0.8 \%(\mathrm{w} / \mathrm{v})$ agarose gel (Seakem Gold agarose, FMC Bioproducts) and a second CHEF gel was run under the following conditions: $48 \mathrm{~h}, 3.0 \mathrm{Vcm}^{-1}, 500$-second pulse, $\pm 106^{\circ}$ field angle; $0.5 \mathrm{X} \mathrm{TBE}$ at $12{ }^{\circ} \mathrm{C}$.

\section{Results}

Intact chromosomes of strain $\mathrm{H} 6$ of T. rubrum were identified by CHEF gel electrophoresis (Figure 1). The ini- tial electrophoretic conditions did not adequately separate the smallest chromosomes (Figure 1A), but a second CHEF gel with conditions optimized for this size range showed a more efficient separation of these chromosomes (Figure 1B). Under the conditions used here, at least five chromosome bands were detected. Assuming a linear separation, comparison with the $S$. pombe and $H$. wingei molecular weight standards showed that these bands were 3.0, 3.05, 4.6, 5.6 and 5.8 Mbp in size. The chromosomes shown in Figure 1 have been numbered according to size, starting with the largest. This numbering is arbitrary and does not take into consideration the presence of possible co-migrating chromosomes.

\section{Discussion}

CHEF gel electrophoresis showed that the molecular karyotype of the clinical isolate $\mathrm{H} 6$ of $T$. rubrum consists of five chromosomal bands which range in size from 3.0 Mbp to $5.8 \mathrm{Mbp}$, and correspond to a total genome size of $22.05 \mathrm{Mbp}$. Thus, at least $22.05 \mathrm{Mbp}$ of the genome are organized as chromosomal macromolecules. Table 1 shows the chromosome and genome sizes of other fungi compared to T. rubrum.

Chromosome length polymorphisms are common in fungi (Skinner et al., 1991) and variations in the molecular karyotype of $T$. rubrum may exist among different isolates. Such variability has been observed in yeast and fungal species such as Candida albicans (Pittet et al., 1991) and Septoria nodorum (Cooley and Caten, 1991), and may reflect chromosomal rearrangements, such as deletions, duplications and translocations, as well as different degrees of pathogenicity in the same species. CHEF analysis is useful in fungal epidemiological studies, and has revealed interand intraspecies variations in Candida infections (Pittet $e t$ al., 1991). The genetic variability of T. rubrum isolates has been demonstrated by sequence analysis of the $18 \mathrm{~S}$ rDNA gene combined with morphological and enzymatic analysis (Nascimento and Martinez-Rossi, 2001).

The ability to separate intact chromosomes has led to the assignment of cloned genes to chromosomal locations without the need for crosses or progeny tests. Any cloned DNA segment may be assigned to a chromosome by Southern hybridization experiments (Skinner et al., 1991; Scherer and Magee, 1990). This strategy has been used to locate the MDR-like genes $A f u M D R 1$ and $A f u M D R 2$ of $A$. fumigatus (Tobin et al., 1997).

In addition to establishing the number and size of $T$. rubrum chromosomes, the present results open perspectives for constructing chromosome-specific libraries, for determining the presence of translocations, duplications and deletions, and for identifying the chromosomal location of genes of interest. This information should facilitate genetic linkage studies in this pathogen. The construction of a genetic map for T. rubrum will be useful for cloning genes of interest by "chromosome walking" to cognate 


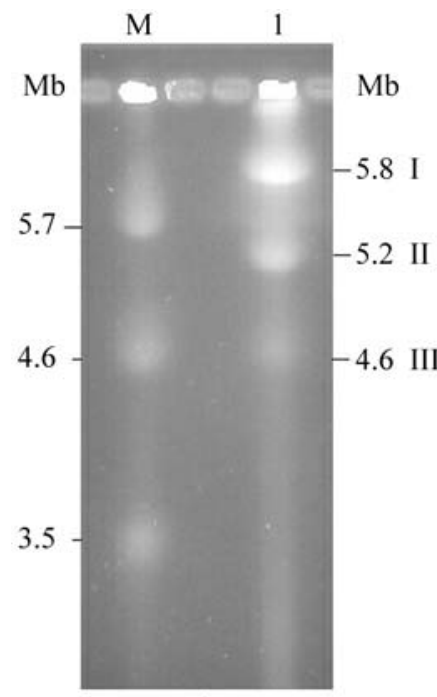

A

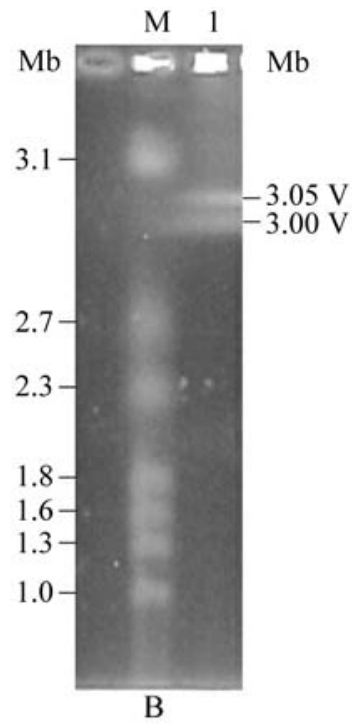

Figure 1 - CHEF electrophoretic karyotype of strain H6 of T. rubrum (1). (A) Separation of intact chromosomal DNAs (I to III) by CHEF in a $0.7 \%$ (w/v) agarose gel. $\mathrm{M}$ is the S. pombe standard. (B) Optimized CHEF separation of chromosomes IV and $\mathrm{V}$ in a $0.8 \%(\mathrm{w} / \mathrm{v})$ agarose gel. $\mathrm{M}$ is the $H$. wingei standard. The approximate lengths of the chromosomal bands are indicated.

genes (Agnan et al., 1997). The information obtained will contribute to our understanding of the genomic organization of this dermatophyte. Finally, determination of the $T$. rubrum genome size is important in order to determine the genome coverage of any genomic library of this fungus to be used in genome projects. The sequencing of the $T$. rubrum genome, together with that of 14 other fungi, has recently been proposed as part of the Fungal Genome Initiative (FGI) (http://www-genome.wi.mit.edu/seq/fgi). This project will allow the application of genomic technologies to the study of fungal pathogenicity, and is particularly important given the limited usefulness of classic genetic approaches for studying this species.

\section{References}

Agnan J, Korch C and Selitrennikoff C (1997) Cloning heterologous genes: problems and approaches. Fungal Genet Biol 21:292-301

Brody H and Carbon J (1989) Electrophoretic karyotype of Aspergillus nidulans. Proc Natl Acad Sci USA 86:62606263.

Chavez R, Fierro F, Gordillo F, Francisco Martin J and Eyzaguirre J (2001) Electrophoretic karyotype of the filamentous fungi Penicillium purpurogenum and chromosomal localization of several xylanolytic genes. FEMS Microbiol Lett 205:379-383.

Cooley RN and Caten CE (1991) Variation in electrophoretic karyotype between strains of Septoria nodorum. Mol Gen Genet 228:17-23.

Costa M, Passos XS, Souza LK, Miranda AT, Lemos J de A, Oliveira JG Jr and Silva M do R (2002) Epidemiology and etiology of dermatophytosis in Goiania, GO, Brazil. Rev Soc Bras Med Trop 35:19-22.

Fachin AL, Maffei CML and Martinez-Rossi NM (1996) In vitro susceptibility of Trichophyton rubrum isolates to griseofulvin and tioconazole. Induction and isolation of a resistant mutant to both antimycotic drugs. Mycopathologia 135:141-143.

Fodor E, Dosa E, Nagy E and Ferenczy L (2002) Karyotyping of Candida albicans and Candida glabrata isolates from recurrent vaginal infections by pulsed-field gel electrophoresis. Acta Microbiol Immunol Hung 49:59-68.

Higtower RC, Callahan TM and Upchurch RG (1995) Electrophoretic karyotype of Cercospora kikuchii. Curr Genet 27:290292.

Jennings MB, Weinberg JM, Koestenblatt EK and Lesczczynski C (2002) Study of clinically suspected onychomycosis in a podiatric population. $\mathrm{J}$ Am Podiatr Med Assoc 92:327-330.

McCluskey K and Mills D (1990) Identification and characterization of chromosome length polymorphisms among strains representing fourteen races of Ustilago hordei. Mol Plant Microbe Interact 3:336-373.

Table 1 - Electrophoretic karyotypes of various fungi.

\begin{tabular}{lcccl}
\hline Fungus & $\begin{array}{c}\text { Number of chromo- } \\
\text { somes (haploid) }\end{array}$ & $\begin{array}{c}\text { Chromosome size } \\
\text { range (Mbp) }\end{array}$ & $\begin{array}{c}\text { Genome size } \\
\text { (Mbp) }\end{array}$ & Reference \\
\hline Aspergillus fumigatus & 5 & $1.7-4.8$ & 15.8 & Tobin et al. (1997) \\
Aspergillus nidulans & 8 & $0.4-4$ & 31 & Brody and Carbon (1989) \\
Aspergillus niger & 8 & $3.5-6.6$ & $35.5-38.5$ & Verdoes et al. (1994) \\
Aspergillus sydowii & 8 & $4-8$ & 40 & Schmitt et al. (2002) \\
Cercospora kikutchii & 8 & $2.0-5.5$ & 28.4 & Higtower et al. (1995) \\
Cochliobolus sativus & 15 & $1.25-3.8$ & 33 & Zhong et al. (2002) \\
Neurospora crassa & 7 & $4-12.6$ & 47 & Orbach et al. (1988) \\
Paracoccidioides brasiliensis & 5 & $3.2-10$ & 29.7 & Montoya et al. (1999) \\
Penicillium purpurogenum & 5 & $2.3-7.1$ & 21.2 & Chavez et al. (2001) \\
Trichophyton rubrum & 5 & $3.0-5.8$ & 22.05 & Present paper \\
Ustilago hordei & 20 & $0.17-3.15$ & $18.4-25.9$ & McCluskey and Mills (1990) \\
\hline
\end{tabular}


McGinnis MR (1980) Laboratory handbook of medical mycology. Academic Press, New York, 661 pp.

Monod M, Jaccoud S, Zaugg C, Lechenn B, Baudraz F and Panizzon R (2002) Survey of dermatophyte infections in the Lauseanne area (Switzerland). Dermatology 205:201203.

Montoya AE, Alvarez AL, Moreno MN, Restrepo A and MacEwen JG (1999) Electrophoretic karyotype of environmental isolates of Paracoccidioides brasiliensis. Med Mycol 37:219-222.

Nascimento AM and Martinez-Rossi NM (2001) 18S-rDNA sequencing, enzyme patterns and morphological characterization of Trichophyton isolates. Braz J Microbiol 32:179186.

Orbach MJ, Vollrath D, Davis RW and Yanofsky C (1988) An electrophoretic karyotype of Neurospora crassa. Mol Cell Biol 8:1469-1473.

Pittet D, Monod M, Filthuth I, Frenk E, Suter PM and Auckenthaler R (1991) Contour-clamped homogenous electric field gel electrophoresis as a powerful epidemiologic tool in yeast infections. Am J Med 91:256S-263S.

Scherer S and Magee PT (1990) Genetics of Candida albicans. Microbiol Rev 84:226-241.

Schmitt EK, Eilinghoff B, Olliger R, Decker H and Kuck U (2002) Development of molecular tools for the mulundocandin producer Aspergillus sydowii: DNA-mediated transformation and reporter gene expression. Appl Microbiol Biotechnol 58:625-631.
Sentamilselvi C, Janaki C, Kamalam A and Thambiah AS (1998) Deep dermatophytosis caused by Trichophyton rubrum: a case report. Mycopathologia 142:9-11.

Skinner DZ, Budde AD and Leong SA (1991) Molecular karyotype analysis of fungi. In: Bennet JW and Lasure LL (eds) More gene manipulations in fungi. Academic Press, San Diego, pp 86-113.

Smith KJ, Welsh M and Skelton H (2001) Trichophyton rubrum showing deep dermal invasion directly from the epidermis in immunosuppressed patients. Br J Dermatol 145:344-348.

Squeo RF, Beer R, Silvers D, Weitzman I and Grossman M (1998) Invasive Trichophyton rubrum resembling blastomycosis infection in the immunocompromised host. J Am Acad Dermatol 39:379-380.

Tobin MB, Peery RB and Skatrud PL (1997) An electrophoretic molecular karyotype of a clinical isolate of Aspergillus fumigatus and the localization of the MDR-like genes AfuMDR1 and AfuMDR2. Mycology 29:67-71.

Verdoes JC, Calil MR, Punt PJ, Debets F, Stwart K, Stouthamer AH and Van den Hondel MJJ (1994) The complete karyotype of Aspergillus niger: the use of introduced electrophoretic mobility variation of chromosomes for gene assignment studies. Mol Gen Genet 244:75-80.

Zhong S, Steffenson BJ, Martinez JP and Ciuffetti LM (2002) A molecular genetic map and electrophoretic karyotype of the plant pathogenic fungus Cochliobolus sativus. Mol Plant Microbe Interact 15:481-492.

Zolan ME (1995) Chromosome-length polymorphism in fungi. Microbiol Rev 59:686-698.

Editor: Sergio Olavo Pinto da Costa 